\title{
Transfers and Transmutations: Introduction
}

\author{
Alina Wirries
}

In this volume of the Göttinger Schriften zur Englischen Pbilologie, a range of Bachelor's and Master's theses on topics of Anglophone literature and culture is brought together that seem, at first glance, to be rather too diverse to find a topic that connects them all. They look at family ideals in Victorian literature and Cornish cultural identities, at questions of intertextuality and cosmopolitanism, at the depiction of violence and subversion; and they contain in-depth studies of texts by authors whose combined life-spans cover more than two thousand years: works by Ovid, Shakespeare, Shaw and Robertson, to name but some, form the focus of attention. The papers collected here are diverse not only in topic, but also in style and method. Yet all contributions cast a new light on their respective topics. What binds them together is an interest in changes: in the transfer of textual elements to a new audience, in changing cultural landscapes that are reflected in literary representations, in transmuting ideas and narratives to fit life two centuries on.

Kirstin Runge's paper opens the field with a close reading of the different versions of Venus and Adonis by Ovid and Shakespeare. Her thesis encompasses an in-depth analysis of the stories' characters and their respective significance for the unfolding of the storyline as well as an insight into how the depiction of the various animals that populate Ovid's and Shakespeare's worlds can be interpreted. While this may sound a well-rehearsed topic, she gives her analysis a different twist by focusing on questions of popularity: She considers Shakespeare's reputa- 
tion with readers in his own time and outlines how his version of $V$ enus and Adonis in particular influenced it.

The next paper in the collection shows a somewhat different side to Shakespeare. Anika Droste presents a piece on the depiction and function of violence, power and justice in Shakespeare's works. Unlike Runge, Droste does not focus on Shakespeare's popularity as such but argues that Shakespeare used the Elizabethan stage to address social issues. Her analysis of Titus Andronicus, King Lear and Richard III shows a widespread paranoia in Elizabethan and Jacobean times which resulted in psychological and physical violence, especially against women. Life, Droste claims, was felt to be confusing and dangerous; the concept of a stable and secure context that encompasses and explains everyone's position and function did not fit anymore. The outbreak of violence that the characters on stage experience reflect this, commenting on problems of how the state exercised authority.

In the following paper, Max von Blanckenburg dives into an analysis of family ideals in Wilde's The Importance of Being Earnest and Shaw's Mrs. Warren's Profession, deconstructing concepts of the Victorian mother and father as well as of children and love and marriage. His theoretical background includes both New Historicism and gender theories. Famously, the role of (middle- and upper-class) women was ideologised as that of the 'angel in the house' in the nineteenth century. In reality, though, the situation was very different. In the course of his work, Blanckenburg describes the prevailing Victorian censorship which made voicing criticism against anything - but especially family ideals - difficult. His key argument on the basis of his analysis is that both Wilde and Shaw used their plays as a means of concealed criticism.

Marius Glowsky's work on intertextuality in James Hogg's Confessions of a Justified Sinner and James Robertson's The Testament of Gideon Mack take us further into modern literature. Glowsky examines the structuralist assumption that Hogg's text acted as hypotext for The Testament of Gideon Mack, which therefore effectively becomes the hypertext. Glowsky discusses theories by various narratologists Genette, Kristeva and Bakhtin - to formulate an analytical approach of his own. This he employs to show how the two texts build up on one another, and how Robertson transformed the already quite modern structure of Hogg's Gothic novel even further.

Benjamin Schlink's paper on the construction of Cornish identities moves us away from literary and towards more encompassing cultural concerns. Stuart Hall's and Benedict Anderson's theories on community and identity form the groundwork of Schlink's approach, but, as shown by his empirical work, have certain faultlines. Schlink's basic assumption is that Cornish people conceive of themselves as member of a separate Cornish nation which, however, does not exist in legal terms. Schlink can therefore use Anderson's concept of an imagined community for explaining his empirical result, as there are linguistic and also cultural factors that contribute to the Cornish perception of their cultural group; 
however, attempting to use criteria distilled from Anderson's and Hall's theories in the context of nationalist thinking shows that both theories have to be amended. It is especially questions of linguistics, of the separateness of a particular language, that is not taken into account by either author, but also the fact that those who consider themselves as belonging to a Cornish nation do so by referring to Cornwall as a closely circumscribed geographical area. Working from an admittedly slender data basis, Schlink's contribution nevertheless points towards shortcomings in the theories used.

An innovative and in-depth paper on cosmopolitanism and the concepts of world citizenship by Nicolas Helm closes the volume. In his stylistically very different paper, Helm charts the nature of cosmopolitanism and its development from the classical up to the postcolonial age using various concepts by Diogenes, Kant, Bhabha and other theorists as his theoretical framework. His main interest is in analysing in how far postcolonial ideas of integrating different elements of ntional identities to form new 'inter-identities' are based on older Western concepts of cosmopolitanism. After all, today's wide-ranging processes of globalisation seem to erase national borders and point towards a more international and border-ignoring - i.e. cosmopolitan in the original sense of the word - localisation of identity.

Change, then, is the thread that runs through all of the papers: Runge and Glowsky both look at changes of genre, at the different uses of textual elements that one author takes from another, and situate these firmly in new cultural and literary contexts. Helm and Schlink discuss new approaches to questions of cultural identity and belonging; the one by ranging far afield, while the other lays the focus on a relatively small geographical area. Droste and Blanckenburg analyse the functions of canonical texts as indicators of social change and social criticism. Taken together, the papers do not only highlight new and interesting ideas on Anglophone literature and culture but also show a high level of analytical and critical competence. 